\title{
Robust Resilience of the Frontotemporal Syntax System to
} Aging

\author{
Karen L. Campbell, ${ }^{1 \star}$ Dávid Samu, ${ }^{1 *}$ (OSimon W. Davis, ${ }^{2}$ Linda Geerligs, ${ }^{3}$ Abdur Mustafa, ${ }^{3}$ and Lorraine K. Tyler, ${ }^{1}$ for \\ Cambridge Centre for Aging and Neuroscience ${ }^{4}$ \\ ${ }^{1}$ Department of Psychology, University of Cambridge, Cambridge CB2 3EB, United Kingdom, ${ }^{2}$ Center for Cognitive Neuroscience, Duke University, \\ Durham, North Carolina 27708, ${ }^{3} \mathrm{MRC}$ Cognition and Brain Sciences Unit, Cambridge CB2 7EF, United Kingdom, and ${ }^{4} \mathrm{Cambridge}$ Centre for Ageing and \\ Neuroscience (Cam-CAN), University of Cambridge and MRC Cognition and Brain Sciences Unit, Cambridge CB2 3EB, United Kingdom
}

Brain function is thought to become less specialized with age. However, this view is largely based on findings of increased activation during tasks that fail to separate task-related processes (e.g., attention, decision making) from the cognitive process under examination. Here we take a systems-level approach to separate processes specific to language comprehension from those related to general task demands and to examine age differences in functional connectivity both within and between those systems. A large population-based sample ( $N=111 ; 22-87$ years) from the Cambridge Centre for Aging and Neuroscience (Cam-CAN) was scanned using functional MRI during two versions of an experiment: a natural listening version in which participants simply listened to spoken sentences and an explicit task version in which they rated the acceptability of the same sentences. Independent components analysis across the combined data from both versions showed that although task-free language comprehension activates only the auditory and frontotemporal (FTN) syntax networks, performing a simple task with the same sentences recruits several additional networks. Remarkably, functionality of the critical FTN is maintained across age groups, showing no difference in within-network connectivity or responsivity to syntactic processing demands despite gray matter loss and reduced connectivity to task-related networks. We found no evidence for reduced specialization or compensation with age. Overt task performance was maintained across the lifespan and performance in older, but not younger, adults related to crystallized knowledge, suggesting that decreased between-network connectivity may be compensated for by older adults' richer knowledge base.

Key words: aging; functional connectivity; ICA; language comprehension; syntax; task demands

Significance Statement

Understanding spoken language requires the rapid integration of information at many different levels of analysis. Given the complexity and speed of this process, it is remarkably well preserved with age. Although previous work claims that this preserved functionality is due to compensatory activation of regions outside the frontotemporal language network, we use a novel systemslevel approach to show that these "compensatory" activations simply reflect age differences in response to experimental task demands. Natural, task-free language comprehension solely recruits auditory and frontotemporal networks, the latter of which is similarly responsive to language-processing demands across the lifespan. These findings challenge the conventional approach to neurocognitive aging by showing that the neural underpinnings of a given cognitive function depend on how you test it.

\section{Introduction}

Several cognitive abilities are thought to decline with age, but these abilities are rarely tested in a process-pure manner. Indeed,

\footnotetext{
Received Dec. 21, 2015; revised March 3, 2016; accepted March 21, 2016.

Author contributions: S.W.D., L.K.T., and Cam-CAN designed research; K.L.C., D.S., S.W.D., and Cam-CAN performed research; K.L.C., D.S., L.G., A.M., L.K.T., and Cam-CAN analyzed data; K.L.C. and L.K.T. wrote the paper.

The Cambridge Centre for Ageing and Neuroscience (Cam-CAN) research is supported by the Biotechnology and Biological Sciences Research Council (Grant BB/H008217/1). We thank the Cam-CAN respondents and their primary care teams in Cambridge for their participation in this study, and colleagues at the MRC Cognition and Brain Sciences Unit MEG and MRI facilities for their assistance. Further information about the Cam-CAN corporate authorship membership can be found at
}

the nature of most cognitive experiments necessarily requires the recruitment of several domain-general processes which are specific to the task itself (e.g., maintenance of task instructions, goal switching; Dosenbach et al., 2006). These additional processes not only affect one's ability to isolate and measure a particular

\footnotetext{
*K.L.C. and D.S. contributed equally to this work.

The authors declare no competing financial interests.

Correspondence should be addressed to Dr. Karen L. Campbell, Department of Psychology, Harvard University, William James Hall, 33 Kirkland Street, Cambridge, MA 02138. E-mail: karencampbell@fas.harvard.edu. DOI:10.1523/JNEUROSCI.4561-15.2016

Copyright $\odot 2016$ the authors $\quad 0270-6474 / 16 / 365214-14 \$ 15.00 / 0$
} 
cognitive function, but they may also affect the neural mechanisms assigned to that function, for instance, giving the impression that a certain process (e.g., memory binding) relies on a wider set of regions (Buckner et al., 1999) than is known to be the case from patient and animal work (Squire, 1992).

This mixing of component processes may be particularly problematic in the study of neurocognitive aging because age differences in the recruitment of domain-general processes may be misattributed to age differences in how the brain performs a specific cognitive process (Grady, 2012; Morcom and Johnson, 2015). For instance, research on syntactic processing with brain-damaged patients emphasizes the dependence of this process on a left-lateralized, frontotemporal system, the computations of which cannot be performed elsewhere in the brain (Caplan et al., 1996; Hagoort et al., 2003). However, several studies of language comprehension and aging show an age-related increase in right frontal activations during syntactic processing (Wingfield and Grossman, 2006), leading to the suggestion that these right hemisphere regions are somehow compensating for the core left-lateralized system, allowing for preserved performance (Peelle et al., 2010; Tyler et al., 2010a). An alternative explanation is that the core syntax system is relatively resilient to age and these additional activations reflect domain-general functions associated with the task itself and not a change in how the aging brain peforms syntactic computations. In line with this view, Davis et al. (2014) recently showed that natural, task-free language comprehension activates the auditory and left-lateralized frontotemporal networks alone, whereas performing an explicit task with the same sentences activates several additional networks, and it is these domain-general networks that show increased activation with age.

Thus, current models of neurocognitive aging may be wrong in important ways. One cannot claim that a given cognitive function has become "dedifferentiated" or "compensated" for without first separating that function from processes related to the task itself (Shafto and Tyler, 2014). Here, we attempt to redress this issue by taking a systems-level approach: identifying networks uniquely associated with specific cognitive functions and then relating functional connectivity both within and between those networks to age, gray matter, and cognitive performance. A large population-based sample from the Cambridge Centre for Aging and Neuroscience (Cam-CAN) was scanned using functional magnetic resonance imaging (fMRI) during two versions of an experiment: an explicit task condition in which participants rated the acceptability of sentences varying in syntactic complexity and a natural listening condition in which they simply listened to the same sentences. Data from both experiments were jointly submitted to an independent components analysis (ICA; Calhoun et al., 2008), which allowed us to separate functional networks uniquely involved in syntactic processing from those associated with overt task performance.

We expected natural listening to solely recruit the auditory and frontotemporal networks, while active task performance should additionally recruit domain-general networks. We also examined the effects of age and experimental task demands on functional connectivity both within and between the ICA-identified networks. Whereas previous work has primarily focused on age differences in connectivity either at rest (Ferreira and Busatto, 2013) or during multicomponential tasks (Sambataro et al., 2010; Spreng and Schacter, 2012), this is the first study to examine systems-level interactions during a task with such well defined and separable neural underpinnings (Tyler et al., 2011). Finally, in light of evidence that prior knowledge can compensate for age-related declines in processing efficiency (Salthouse, 1984; Soederberg Miller, 2009), we test
Table 1. Participant demographics and mean cognitive performance

\begin{tabular}{llll}
\hline Age group & Young & Middle & Older \\
\hline$N$ & 35 & 37 & 39 \\
Age range (years) & $22-45$ & $46-64$ & $65-87$ \\
Sex (male/female) & $17 / 18$ & $18 / 19$ & $20 / 19$ \\
Highest education & & & \\
$\quad$ University & 30 & 23 & 19 \\
$\quad$ A' levels $_{\text {GCSE grade }}$ & 4 & 9 & 11 \\
$\quad 1$ & 5 & 5 \\
None $>16$ & 0 & 0 & 4 \\
Proportion of tones & $0.99(0.03)$ & $0.93(0.11)$ & $0.89(0.16)$ \\
MMSE & $29.34(1.1)$ & $29.08(0.9)$ & $28.08(1.5)$ \\
Crystallized intelligence & $53.71(3.9)$ & $54.38(4.8)$ & $53.23(5.8)$ \\
Fluid intelligence & $37.31(4.4)$ & $33.32(4.6)$ & $27.28(5.5)$ \\
\hline
\end{tabular}

Values in parentheses are standard deviations. Proportion of tones detected on Siemens HearCheck Screener test; MMSE, Mini mental status examination; Crystallized intelligence, Spot-the-Word test; Fluid intelligence, Cattell culture fair test.

whether crystallized intelligence mitigates fluid declines by becoming increasingly related to syntactic performance with age.

\section{Materials and Methods}

\section{Participants}

A population-derived sample $(N=111,22-87$ years old, $\mathrm{M}=54.57$, $\mathrm{SD}=17.84$ ) was recruited as part of the Cam-CAN project (Shafto et al., 2014). Demographic information (including sex) is provided in Table 1. Hearing was assessed using the Siemens HearCheck Screener, which tests participants' ability to detect three sound pressure levels $(75,55$, and 35 $\mathrm{dB}$ SPL) at two frequencies ( 1000 and $3000 \mathrm{~Hz}$ ). Exclusion criteria for the Cam-CAN Stage 2 cohort (who underwent extensive cognitive, MRI and MEG testing) included low performance $(<25)$ on the mini mental state exam (Folstein et al., 1975), poor hearing (failing to hear $35 \mathrm{~dB}$ at $1000 \mathrm{~Hz}$ in both ears), poor vision ( $<20 / 50$ on the Snellen test; Snellen, 1862), non-native English speaker, self-reported substance abuse, current serious health conditions (e.g., self-reported major psychiatric conditions, current chemo/radiotherapy, or a history of stroke), and contraindications to MRI (for full exclusion criteria, see Shafto et al., 2014). Handedness was assessed using the Edinburgh Handedness Inventory and all but two participants were right-handed (excluding these participants from the analyses did not change the pattern or significance of the results). Informed consent was obtained from all participants and ethical approval for the study was obtained from the Cambridgeshire 2 (now East of England-Cambridge Central) Research Ethics Committee.

\section{Cognitive tasks}

Language comprehension. Participants were scanned while listening to spoken sentences that varied in the level of syntactic processing required (Tyler et al., 2011). In both the natural listening and task conditions, sentences contained either a syntactically ambiguous central phrase (e.g., “... cooking apples ...") or an unambiguous phrase that was similar in structure (e.g., “. . . sneering boys”...). Unambiguous sentences $(n=$ 42) had only one possible syntactic interpretation (e.g., "sneering boys are..."), whereas ambiguous sentences had two possible interpretations: one that is more expected or dominant $(n=42)$ given its higher frequency in the language (e.g., "cooking apples are ...") and one that is less expected or subordinate $(n=42)$ given its relative infrequency (e.g., "cooking apples is ..."). This paradigm capitalizes on syntactic ambiguity, a naturally occurring phenomenon in human language, to manipulate the level of syntactic processing required by each sentence. Subordinate sentences require the most processing, as listeners must overturn an automatically activated dominant interpretation (e.g., "cooking apples are inedible without lots of sugar," where "cooking apples" is a noun phrase) in favor of a less expected subordinate interpretation (e.g., "cooking apples is an easy task," where "cooking" functions as a gerund). Dominant sentences still contain ambiguity, and thus are more complex than unambiguous sentences, but the resolution of that ambiguity is in line with the listeners' expectations so no revision is required. Previous work has shown that listeners are sensitive to these 
varying demands, responding slowest to subordinate sentences, followed by dominant, and finally unambiguous sentences (Tyler and MarslenWilson, 1977; Tyler et al., 2013).

During natural listening, participants were simply asked to listen attentively to the sentences, with their eyes open. Sentence stimuli were pseudorandomly intermixed with nonlinguistic baseline items $(n=21)$, consisting of envelope-shaped "musical rain" which shares the complex auditory properties of speech without any of the linguistic meaning (Uppenkamp et al., 2006). During the task version, participants listened to the same sentence and musical rain stimuli, but were now asked to perform an explicit acceptability judgment task. In this task, participants hear the first part of the sentence spoken in a female voice up until the end of the central phrase (e.g., "The class observed that cooking apples ..."), followed by a single word spoken in a male voice (e.g., "are"). Participants' task was to decide whether the final word was an acceptable continuation to the sentence or not. All sentences were grammatically acceptable, but a normal pattern of responding for people without language impairments is to reject more (and respond more slowly to) subordinate sentences than dominant and unambiguous sentences, with little difference between the latter two conditions (Tyler et al., 2011). Thus, we focus primarily on the difference between the subordinate and unambiguous conditions in subsequent behavioral and fMRI analyses reported, as these conditions differ most in syntactic processing demands. One participants' behavioral responses were lost due to equipment error $(N=110$ for all behavioral analyses, including those relating brain to behavior).

Crystallized and fluid intelligence. To examine the potential compensatory role of crystallized knowledge in older adults' maintained performance on the syntax task, we also obtained measures of crystallized and fluid intelligence outside the scanner. Crystallized intelligence was measured using the Spot-the-Word Test (Baddeley et al., 1993), in which participants see word-nonword pairs (e.g., pinnace-strummage) and decide which is a real word. Fluid intelligence was measured using the Cattell Culture Fair (Cattell and Cattell, 1960), a timed pen-and-paper test in which participants perform a series of nonverbal puzzles. Because fluid and crystallized intelligence tend to be moderately correlated (Cattell, 1963; Baddeley et al., 1993), we wanted to control for fluid intelligence in our analyses to isolate the unique contribution of crystallized knowledge. To determine whether crystallized knowledge becomes a stronger predictor of syntax performance with age, we used a moderation model predicting syntax performance from age, crystallized knowledge, and the age $\times$ crystallized knowledge interaction (with fluid intelligence included as a covariate).

\section{MRI acquisition and preprocessing}

Imaging was performed on a 3T Siemens TIM Trio System at the MRC Cognition Brain and Sciences Unit, Cambridge, UK. A 3D-structural MRI was acquired for each subject using T1-weighted sequence [Generalized Autocalibrating Partially Parallel Acquisition; repetition time $(\mathrm{TR})=2250 \mathrm{~ms}$; echo time $(\mathrm{TE})=2.99 \mathrm{~ms}$; inversion time $(\mathrm{TI})=900$ ms; flip angle $\alpha=9^{\circ}$; matrix size $256 \times 240 \times 19 \mathrm{~mm}$; field of view $(\mathrm{FOV})=256 \times 240 \times 192 \mathrm{~mm}$; resolution $=1 \mathrm{~mm}$ isotropic; accelerated factor $=2$ ] with acquisition time of $4 \mathrm{~min}$ and $32 \mathrm{~s}$. For the functional runs, $\mathrm{T} 2{ }^{\star}$-weighted $\mathrm{PMRI}$ data were acquired using a gradientecho echoplanar imaging (EPI) sequence $(\mathrm{TR}=1970 \mathrm{~ms}$; TE $=30 \mathrm{~ms}$; flip angle $=78^{\circ} ; 32$ axial slices of thickness of $3.7 \mathrm{~mm}$ with an interslice gap of $20 \%$; FOV $=192 \times 192 \mathrm{~mm}$; voxel-size $=3 \times 3 \times 4.44 \mathrm{~mm}$ ). The natural listening and task versions were acquired in separate runs, with run times of $15.73 \mathrm{~min}$ (479 volumes) and $16.29 \mathrm{~min}$ (496 volumes), respectively.

Preprocessing was performed using SPM12 (Wellcome Department of Imaging Neuroscience, University College London, London, UK), implemented in the automatic analysis (AA) batching system (; Cusack et al., 2015). The functional images were motion-corrected and slice-time corrected. The T1-weighted images were coregistered to an MNI template image, bias-corrected, and segmented into various tissue classes using unified segmentation (Ashburner and Friston, 2005). The segmented gray matter images were then used to create a study-specific anatomical template, using the DARTEL procedure to optimize interparticipant alignment (Ashburner,
2007), which was then transformed to MNI space. The EPI images were then coregistered to the T1 image, normalized to MNI space using the DARTEL flowfields, and smoothed using an $8 \mathrm{~mm}$ FWHM Gaussian kernel. The segmented gray matter images were also smoothed for subsequent structural analyses using a $10 \mathrm{~mm}$ FWHM Gaussian kernel.

\section{Independent components analysis}

ICA was used to identify networks that were either commonly activated across the two experimental conditions (natural listening and task) or unique to one particular state. All participants' data from both the natural listening and task conditions were temporally concatenated and submitted to the same ICA analysis, using the Group ICA of fMRI Toolbox (; Calhoun et al., 2001). This method decomposes the fMRI signal into a set of independent components, each with a set of individual spatial maps and time courses, which were standardized using Z-scores. Given recent evidence favoring low model order analyses for the purpose of examining large-scale brain networks (Smith et al., 2009; Laird et al., 2011; Ray et al., 2013), and to allow for continuity of comparison with our previous report using similar methods, we set the number of components to 33 (Davis et al., 2014).

Temporal regression was used to select components that related to our four language conditions of interest. We used an event model previously shown to maximize sensitivity to ambiguity by testing only the period immediately following the ambiguous phrase (Tyler et al., 2011). To this end, we defined the onset of each condition separately as the onset of the disambiguating verb following the ambiguous central phrase (or an equivalent point in the unambiguous sentences and musical rain stimuli), with a variable duration equivalent to the remaining length of the phrase (Task: mean duration $=403 \mathrm{~ms}, \mathrm{SD}=30 \mathrm{~ms}$; Natural Listening: mean duration $=1789 \mathrm{~ms}, \mathrm{SD}=451 \mathrm{~ms}$ ). We also included an extra regressor of no interest with onset at the start of each sentence and duration up to the onset of the disambiguating verb (Task and Natural Listening: mean duration $=2185 \mathrm{~ms}, \mathrm{SD}=317 \mathrm{~ms}$ ). This "first-half" regressor does not distinguish between conditions (i.e., it is a single regressor which corresponds to the first half of all sentences, or the equivalent time period for musical rain stimuli), and thus, does not correlate with the disambiguating word regressors. This model tests for effects of the second half of the sentence while controlling for those of the first half. These onsets were then used to create stimulus regressors in SPM12 by convolving the stimulus functions with the canonical hemodynamic response function. Four task conditions were modeled in addition to the first half of the sentences and standard motion regressors (i.e., $x / y / z$ translation, pitch, roll, and yaw): (1) subordinate or unexpected continuations to ambiguous sentences, (2) dominant or highly predicted continuations to ambiguous sentences, (3) matched continuations to syntactically unambiguous sentences, and (4) the acoustic baseline condition. To determine which components related to our conditions of interest, linear regression was used to predict each participant's component time course from the set of task-related and motion regressors. This analysis yields a set of $\beta$ parameters (or "loading values") for each participant (for each condition) indicating the extent to which each of their component time courses relates to each of the task conditions during natural listening and task (similar to standard voxelwise modeling of the same design matrix, but with far fewer comparisons).

To identity networks related to our conditions of interest, components were rank-ordered according to their mean loading values (i.e., $\beta$ parameters) across the language conditions (subordinate, dominant, and unambiguous). The seven strongest components were selected for further analysis, as subsequent components appeared to capture artifact. Conventional significance testing of the $\beta$ parameters (i.e., against zero; $\mathrm{St}$ Jacques et al., 2011) was not appropriate in this case, as almost all components were highly significant due to the large sample size. Loading values from the seven language-related networks were then tested for the effects of task (task, natural listening) and language (subordinate, unambiguous) using a $2 \times 2$ multivariate ANOVA (MANOVA). As discussed in the Language comprehension section above, we focus primarily on the difference between the subordinate and unambiguous conditions, as these conditions differ most in syntactic processing demands. Network responsivity to syntactic processing demands (i.e., subordinate- 
unambiguous loadings) was then related to age, gray matter, and task performance using Pearson's correlations (95\% confidence intervals were calculated for each correlation using a bootstrap estimate with 1000 samples). All correlation analyses were Bonferroni-corrected for multiple comparisons. Gray matter estimates for each network were obtained by first creating masks using the component spatial maps (thresholded at $Z>2.58$, equivalent to $p<0.01$ ) and then extracting mean gray matter within those masks from the segmented gray matter images.

Within-network connectivity was quantified as the average correlation of the raw fMRI time course between all pairs of voxels within the thresholded component maps (after detrending the time courses and compensating for motion artifacts by regressing out the 6 realignment parameters, their derivatives, squared terms, and squared derivatives; Satterthwaite et al., 2013). Between-network connectivity was quantified as the correlation between pairs of component time courses (Allen et al., 2011; Arbabshirani et al., 2013). Similar to the calculation of within-network connectivity, motion parameters were regressed out of the subject-specific time courses and these were detrended before pairwise correlations were computed between each of the seven components. For all statistical analyses, correlations were transformed to Z-scores using Fisher's transformation, $z=\operatorname{atanh}(k)$, where $k$ is the Pearson's correlation coefficient between two network time courses. Within- and between-network connectivity were then related to age, gray matter, and task performance using Pearson's correlations $(p<0.05$, Bonferroni-corrected, 95\% bootstrap confidence intervals).

\section{Results}

\section{Summary of main findings}

To guide the reader, we preface our main results here. We find that: (1) overt task performance is preserved with age, in that older adults' RTs vary to the same extent as younger adults in response to syntactic processing demands; (2) natural listening only recruits auditory (AUD) and frontotemporal (FTN) networks, whereas performing a task with the same stimuli recruits several additional domain-general networks; (3) responsivity of these networks to syntactic processing demands did not differ with age or gray matter concentration (GMC), but did predict overt task performance, with the multiple demand network $(\mathrm{MDN})$ as the strongest predictor (an effect that was not moderated by age); (4) within-network connectivity during the task (not natural listening) decreased with age/GMC loss in some domain-general networks, but not in the critical FTN; (5) between-network connectivity declined with age/GMC for several network pairs during the task, and only connectivity between the critical FTN and other domain-general networks predicted performance; and finally, (6) crystallized knowledge became increasingly related to performance with age.

\section{Behavioral data}

On the syntax task, our critical measure of interest was the extent to which reaction times (RTs) varied as a function of syntactic processing demands (Tyler et al., 2013). Anticipatory responses $(<200 \mathrm{~ms})$ were removed $(<1 \%$ of trials) and RT data were inverse transformed (Ratcliff, 1993) before calculating cell means per condition per subject (means were then reverse-transformed to standard millisecond units). Mean RTs were submitted to an ANOVA with condition [subordinate (most demanding), dominant, and unambiguous (least demanding); see Materials and Methods] as a within-subjects factor and age as a continuous covariate. There was a main effect of condition, $F_{(2,216)}=16.41$, $p<0.001, \eta_{p}^{2}=0.13$, with participants responding more slowly to subordinate continuations $(\mathrm{M}=1330 \mathrm{~ms}, \mathrm{SD}=384)$ than dominant continuations $\left[\mathrm{M}=1125 \mathrm{~ms}, \mathrm{SD}=381 ; t_{(109)}=12.14\right.$,
$M_{\text {diff }}=205.76, p<0.001,95 \%$ CI $\left.(172.00,239.53), d=1.16\right]$, which in turn were slower than unambiguous sentences $[\mathrm{M}=$ $1056 \mathrm{~ms}, \mathrm{SD}=390 ; t_{(109)}=5.79, M_{\mathrm{diff}}=68.32, p<0.001,95 \%$ CI $(44.83,91.80), d=0.55]$. There was also a main effect of age $F_{(1,108)}=48.73, p<0.001, \eta_{p}^{2}=0.31$, due to older adults responding more slowly on average (Fig. $1 a$; note that age is always treated as a continuous variable throughout the analyses, though sometimes shown as a categorical variable for visualization purposes, as in Fig. 1a). Importantly, the age $\times$ condition interaction was not significant, $F<1$, confirming that our syntactic manipulation had the same effect on RTs across the lifespan. We also calculated a syntactic sensitivity measure as the difference in RTs to subordinate and unambiguous sentences for each subject and correlated this measure with age. As can be seen in Figure $1 b$, syntactic sensitivity did not differ with age, $r=-0.01, p=0.88$. These results are in line with previous results showing no effect of age on syntactic processing within this task (Tyler et al., 2010a; Davis et al., 2014).

\section{Independent components analysis}

\section{Effects of task and syntactic processing demands}

To separate task-related networks from those specific to language processing, we performed an ICA over the combined data from task and natural listening. This analysis identified seven components that related to language processing (Fig. 2). These included: (1) a left-lateralized FTN including the left inferior frontal gyrus (BA45 and BA47) and middle temporal gyrus (MTG; BA22) similar to previously reported (Tyler et al., 2011); (2) an extended AUD network which included primary auditory cortex, extending into superior temporal gyrus and, to a more limited extent, MTG; (3) a bilateral frontal network highly similar to the previously established MDN (Duncan, 2010), comprising bilateral middle and inferior frontal gyri, a superior medial frontal region, and (just below threshold, at $Z>2.3$ ) the left intraparietal sulcus; (4) an opercular (OPRC) network including anterior cingulate cortex and bilateral anterior insula; (5) a basal ganglia (BG) network; (6) a bilateral motor (MOT) network; and (7) a negatively loading default mode network (DMN).

To determine the effect of the experimental manipulations on network activity, we submitted condition-specific loading values (i.e., $\beta$ parameters) for our seven event-related networks to a $2 \times$ 2 MANOVA with Task (task, natural listening) and Language (subordinate, unambiguous) as within-subject factors. Reporting the results of the omnibus multivariate tests first, overall there were main effects of Task: $T=7.31, F_{(7,104)}=108.62, p<0.001$, $\eta_{p}^{2}=0.88$, and Language: $T=3.26, F_{(7,104)}=48.39, p<0.001$, $\eta_{p}^{2}=0.77$, and a significant interaction between Task and Language: $T=1.85, F_{(7,104)}=27.47, p<0.001, \eta_{p}^{2}=0.65$. As Table 2 shows, there was a main effect of Task for all seven networks, and a main effect of Language for all networks except the DMN. Further, the Task $\times$ Language interaction was significant for all networks, with the largest effect seen for the MDN. Pairwise comparisons revealed that during the task, there was significantly greater activity in response to subordinate than unambiguous sentences in all networks except the DMN (Table 2). Critically, during natural listening, only the FTN and AUD networks increased activation in response to syntactic processing demands (i.e., subordinate $>$ unambiguous; Table 2). Although three other networks showed a significant difference between Language conditions, none of these showed greater activation to the language conditions relative to the musical rain baseline (Fig. 2). Together, these results suggest that although natural listening 

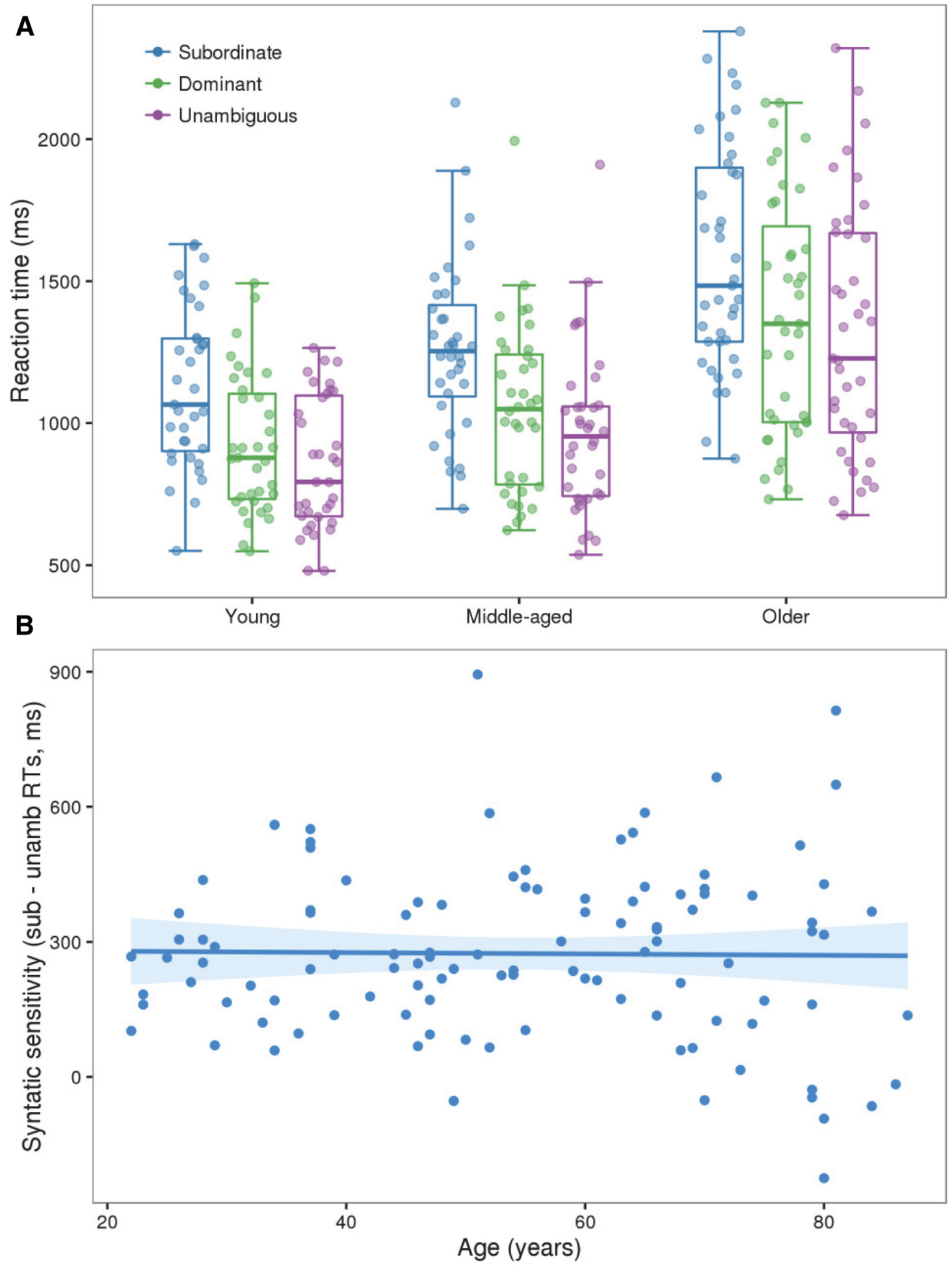

Figure 1. A, Mean RTs for the subordinate, dominant, and unambiguous conditions (dots represent individual datapoints, with a boxplot overlaid). Data are split into three age groups detailed in Table 1. B, Scatterplot showing the relationship between age and syntactic sensitivity (i.e., subordinate- unambiguous RTs).

recruits language-specific networks, which are sensitive to syntactic processing demands, when listeners hear the same sentences within the context of an explicit task, a dissociable set of domain-general networks are also activated.

\section{Relationship to age and gray matter}

What effect do increasing age and gray matter decline have on the ability of these networks to respond to syntactic processing de- mands (i.e., subordinate- unambiguous loadings) during natural listening and task conditions? Looking at the effect of age during natural listening, there was no age-related difference in network responsivity during task-free language comprehension (Table 3 ). In fact, even during the task, network responsivity was not significantly related to age (Table 3 ; smallest $p=0.03$ for the FTN, which does not survive Bonferroni correction). Further, despite 


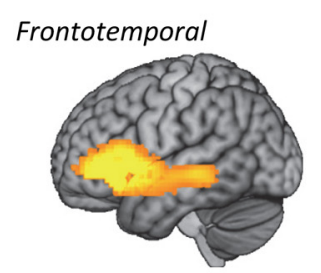

Auditory

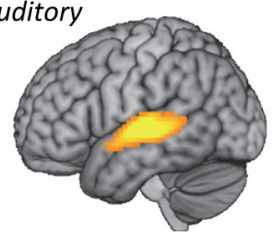

Multiple demand

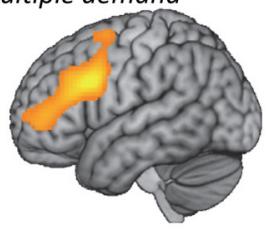

Opercular

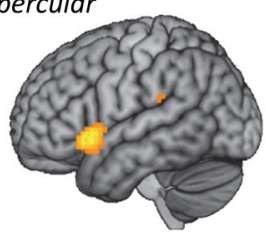

Basal ganglia
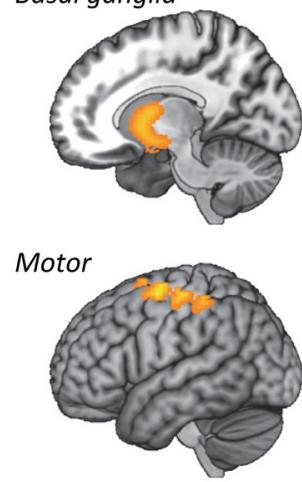

Default mode
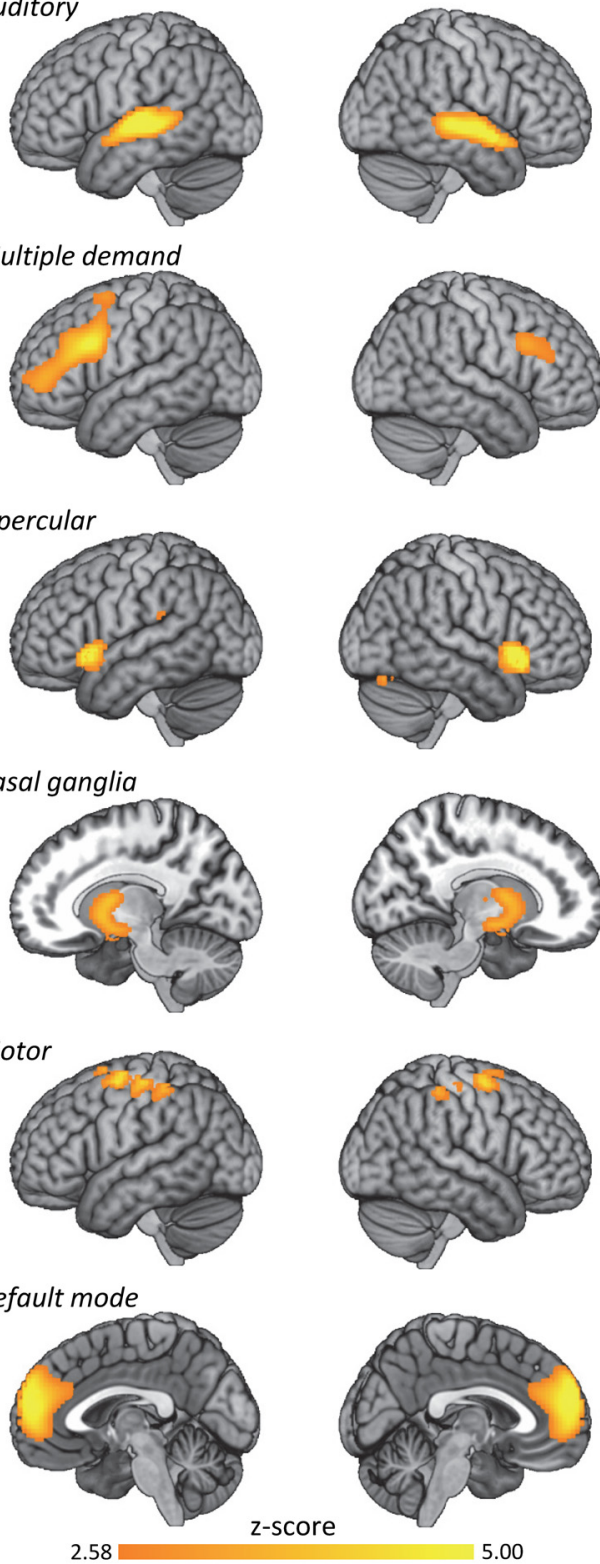
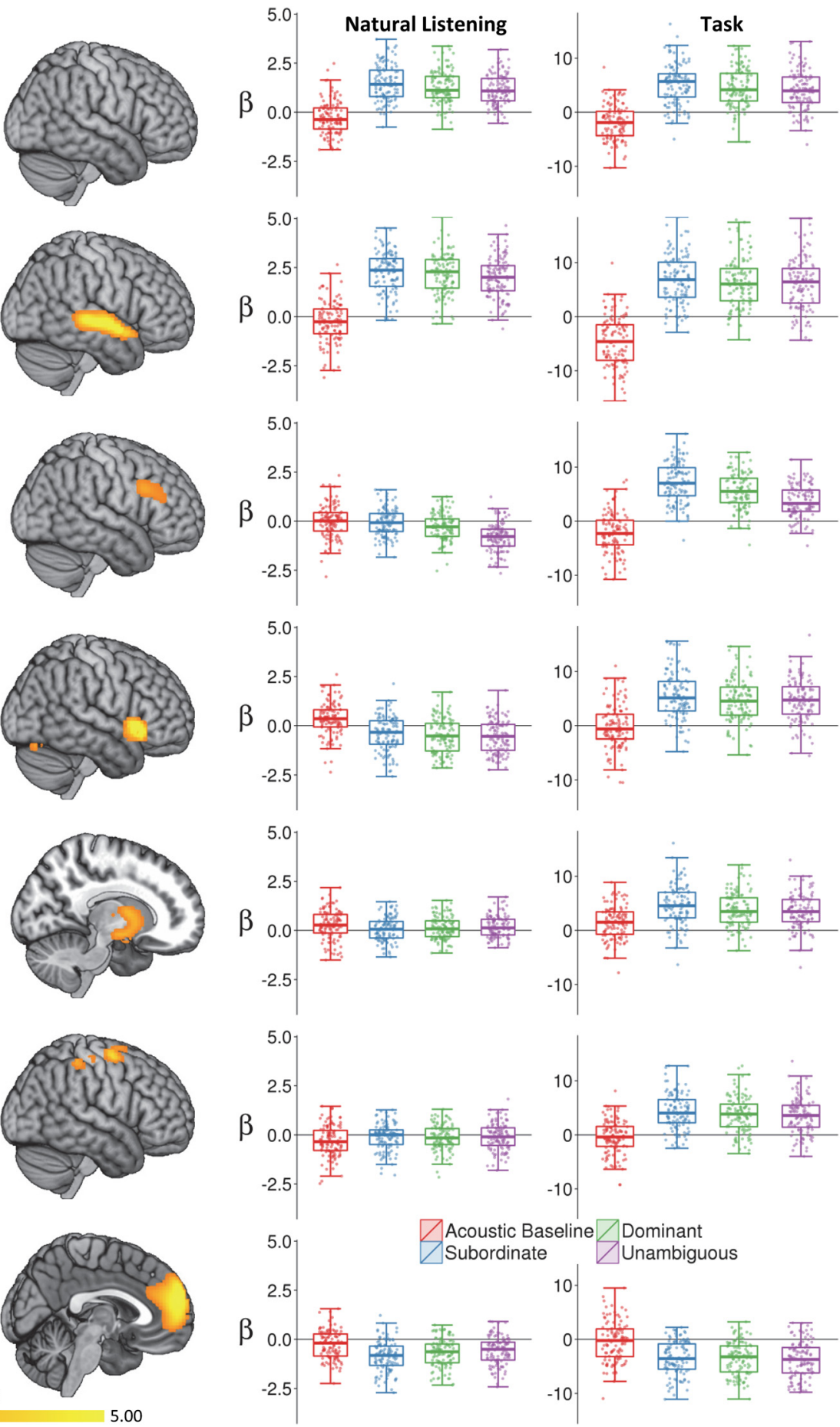

Figure 2. Functional networks differentially active during natural listening and task. Left, The group average spatial map for each component rendered on a canonical brain. Right, Individual loading values (with a boxplot overlaid) for each network during Natural Listening and Task for the four conditions (acoustic baseline, subordinate, dominant, and unambiguous).

the robust decline in mean GMC within each network with age (Table 3), individual differences in network GMC did not relate to network responsivity, either during natural listening (Table 4; smallest $p=0.02$ for MDN, which does not survive correction) or during the task (Table 4 ; smallest $p=0.048$ for the FTN, which does not survive correction). These findings suggest that syntactic processing, even within the context of an artificial task, is relatively robust to both age and age-related structural declines.
Relationship to performance

What is the strongest predictor of overt task performance responsivity of the syntax system itself or that of the domaingeneral networks? Performance was measured as the difference in RTs to subordinate and unambiguous sentences (i.e., our "syntactic sensitivity" measure above) and was positively correlated to responsivity of the FTN $\left(r_{110}=0.19, p<0.05\right), \operatorname{AUD}\left(r_{110}=0.23\right.$, $p<0.05), \operatorname{MDN}\left(r_{110}=0.38, p<0.001\right)$, and BG $\left(r_{110}=0.22\right.$, $p<0.05$ ) during the task (only MDN survives Bonferroni cor- 
Table 2. Main effects and interactions of Task and Language condition in the seven ICA networks related to language processing

\begin{tabular}{|c|c|c|c|c|c|c|c|c|c|c|c|c|c|c|c|}
\hline \multirow[b]{3}{*}{ Component } & \multicolumn{9}{|l|}{ ANOVA } & \multicolumn{6}{|l|}{ Pairwise comparisons } \\
\hline & \multicolumn{3}{|l|}{ Task } & \multicolumn{3}{|c|}{ Language } & \multicolumn{3}{|c|}{ Task $\times$ language } & \multicolumn{3}{|c|}{ Sub vs unamb during task } & \multicolumn{3}{|c|}{ Sub vs unamb during natural listening } \\
\hline & $F$ & $p$ & $\eta_{p}^{2}$ & $F$ & $p$ & $\eta_{p}^{2}$ & $F$ & $p$ & $\eta_{p}^{2}$ & $M_{\text {diff }}(95 \%$ Cl) & $t(108)$ & $p$ & $M_{\text {diff }}(95 \%$ Cl) & $t(108)$ & $p$ \\
\hline Frontot & 108.99 & $<0.001$ & 0.49 & 51.73 & $<0.001$ & 0.32 & 15.11 & $<0.001$ & 0.12 & $1.12(0.73,1.50)$ & 5.77 & $<0.001$ & $0.36(0.23,0.48)$ & 5.87 & $<0.0$ \\
\hline Auditory & 103.62 & $<0.001$ & 0.48 & 32.46 & $<0.001$ & 0.23 & 7.25 & $<0.01$ & 0.06 & $0.76(0.40,1.12)$ & 4.20 & $<0.001$ & $0.27(0.17,0.38)$ & 4.97 & $<0.001$ \\
\hline Multiple demand & 375.35 & $<0.001$ & 0.77 & 302.69 & $<0.001$ & 0.73 & 139.29 & $<0.001$ & 0.56 & $3.48(3.02,3.94)$ & 15.03 & $<0.001$ & $0.77(0.64,0.90)$ & 11.78 & $<0.001$ \\
\hline Opercular & 215.63 & $<0.001$ & 0.66 & 18.76 & $<0.001$ & 0.15 & 10.27 & $<0.01$ & 0.08 & $0.88(0.42,1.34)$ & 3.82 & $<0.001$ & $0.13(-0.002,0.26)$ & 1.95 & 0.0 \\
\hline Basal ganglia & 154.56 & $<0.001$ & 0.58 & 27.57 & $<0.001$ & 0.20 & 47.61 & $<0.001$ & 0.30 & $1.09(0.74,1.45)$ & 6.09 & $<0.001$ & $-0.11(-0.21,-0.03)$ & 2.66 & $<0.01$ \\
\hline Motor & 164.71 & $<0.001$ & 0.60 & 17.22 & $<0.001$ & 0.13 & 18.95 & $<0.001$ & 0.15 & $0.71(0.38,1.04)$ & 4.28 & $<0.001$ & $-0.01(-0.11,0.08)$ & -0.29 & 0.77 \\
\hline Default mode & 99.61 & $<0.001$ & 0.47 & $<1$ & 0.99 & 0.00 & 7.99 & $<0.01$ & 0.07 & $0.28(-0.12,0.67)$ & 1.39 & 0.17 & $-0.27(-0.37,-0.17)$ & 5.21 & $<0.001$ \\
\hline
\end{tabular}

Results on the left are from follow-up ANOVAs testing the main effect of Task (task, natural listening) and Language [subordinate (sub); unambiguous (unamb)], as well as the Task $\times$ Language interaction on the loading value (i.e., $\beta$ parameters) for each component. Results on the right are from paired samples $t$ test testing the difference between subordinate and unambiguous $\beta$ parameters separately during Task and Natural Listening.

Table 3. Pearson's correlation between age and mean grey matter concentration, responsivity, and within-network connectivity for each component

\begin{tabular}{|c|c|c|c|c|c|c|c|c|c|c|}
\hline \multirow[b]{3}{*}{ Component } & \multirow{2}{*}{\multicolumn{2}{|c|}{ GMC }} & \multicolumn{4}{|l|}{ Responsivity } & \multicolumn{4}{|l|}{ WNC } \\
\hline & & & \multicolumn{2}{|l|}{ Task } & \multicolumn{2}{|l|}{ Natural listening } & \multicolumn{2}{|l|}{ Task } & \multicolumn{2}{|l|}{ Natural listening } \\
\hline & $r(95 \% \mathrm{Cl})$ & $p$ & $r(95 \% \mathrm{Cl})$ & $p$ & $r(95 \% \mathrm{Cl})$ & $p$ & $r(95 \% \mathrm{Cl})$ & $p$ & $r(95 \% \mathrm{Cl})$ & $p$ \\
\hline Frontotemporal & $-0.56(-0.67,-0.44)$ & $<0.001$ & $-0.21(-0.37,-0.03)$ & 0.03 & $-0.08(-0.27,0.10)$ & 0.39 & $0.03(-0.13,0.20)$ & 0.73 & $0.14(-0.04,0.32)$ & 0.14 \\
\hline Auditory & $-0.49(-0.62,-0.36)$ & $<0.001$ & $-0.16(-0.33,0.02)$ & 0.09 & $-0.10(-0.25,0.08)$ & 0.31 & $-0.20(-0.35,-0.04)$ & 0.04 & $-0.04(-0.23,0.15)$ & 0.65 \\
\hline Multiple demand & $-0.64(-0.73,-0.52)$ & $<0.001$ & $-0.15(-0.32,0.03)$ & 0.11 & $-0.16(-0.33,0.02)$ & 0.09 & $-0.21(-0.35,-0.04)$ & 0.03 & $-0.06(-0.25,0.13)$ & 0.52 \\
\hline Opercular & $-0.61(-0.71,-0.50)$ & $<0.001$ & $0.03(-0.17,0.23)$ & 0.78 & $-0.01(-0.18,0.16)$ & 0.92 & $-0.24(-0.39,-0.06)$ & 0.01 & $-0.09(-0.28,0.12)$ & 0.37 \\
\hline Basal ganglia & $-0.55(-0.67,-0.43)$ & $<0.001$ & $0.07(-0.13,0.25)$ & 0.49 & $0.06(-0.12,0.22)$ & 0.56 & $-0.45(-0.56,-0.33)$ & $<0.001$ & $-0.30(-0.45,-0.13)$ & 0.001 \\
\hline Motor & $-0.57(-0.69,-0.43)$ & $<0.001$ & $0.15(-0.04,0.33)$ & 0.13 & $0.14(-0.03,0.32)$ & 0.15 & $0.14(-0.06,0.33)$ & 0.15 & $0.21(0.002,0.38)$ & 0.03 \\
\hline Default mode & $-0.55(-0.66,-0.41)$ & $<0.001$ & $-0.05(-0.24,0.15)$ & 0.63 & $0.10(-0.08,0.28)$ & 0.29 & $0.05(-0.12,0.24)$ & 0.61 & $0.16(-0.04,0.36)$ & 0.10 \\
\hline
\end{tabular}

Responsivity (to syntactic processing demands), Subordinate- unambiguous loadings; WNC, Within-network connectivity.

$\mathrm{Cl}=95 \%$ bootstrap confidence intervals.

Table 4. Pearson's correlation between GMC and network responsivity and WNC

\begin{tabular}{|c|c|c|c|c|c|c|c|c|}
\hline \multirow[b]{3}{*}{ Component } & \multicolumn{4}{|l|}{ Responsivity } & \multicolumn{4}{|l|}{ WNC } \\
\hline & \multicolumn{2}{|l|}{ Task } & \multicolumn{2}{|l|}{ Natural listening } & \multicolumn{2}{|l|}{ Task } & \multicolumn{2}{|l|}{ Natural listening } \\
\hline & $r(95 \% \mathrm{Cl})$ & $p$ & $r(95 \% \mathrm{Cl})$ & $p$ & $r(95 \% \mathrm{Cl})$ & $p$ & $r(95 \% \mathrm{Cl})$ & $p$ \\
\hline Auditory & $0.06(-0.11,0.23)$ & 0.53 & $-0.06(-0.26,0.16)$ & 0.52 & $0.22(0.04,0.38)$ & 0.02 & $0.17(-0.004,0.34)$ & 0.07 \\
\hline Multiple demand & $0.11(-0.09,0.31)$ & 0.24 & $0.21(0.07,0.35)$ & 0.02 & $0.34(0.18,0.47)$ & $<0.001$ & $0.18(0.03,0.33)$ & 0.06 \\
\hline Opercular & $-0.07(-0.27,0.11)$ & 0.44 & $0.03(-0.19,0.23)$ & 0.79 & $0.31(0.16,0.44)$ & 0.001 & $0.24(0.09,0.39)$ & 0.01 \\
\hline Default mode & $0.07(-0.14,0.28)$ & 0.50 & $-0.12(-0.31,0.08)$ & 0.20 & $0.05(-0.13,0.23)$ & 0.57 & $-0.01(-0.20,0.19)$ & 0.95 \\
\hline
\end{tabular}

Correlation values for each component are between mean GMC within that component and (1) its responsivity to syntactic processing demands (ie., subordinate- unambiguous loadings; first two columns) and (2) its mean within-network connectivity (WNC; second two columns).

$\mathrm{Cl}=95 \%$ bootstrap confidence intervals.

rection). If we enter all seven networks into the same regression predicting task performance, the overall model is significant: $R^{2}$ $=0.19, F_{(7,102)}=3.31, p<0.01$, and only MDN responsivity is a significant predictor $[\beta=0.37, t=3.29, p<0.01,95 \% \mathrm{CI}(0.14$, 0.58 ); for this and all subsequent regression analyses, we report standardized coefficients]. Thus, despite the fact that syntactic processing critically depends on a left-lateralized frontotemporal system (Caplan et al., 1996; Hagoort et al., 2003; Tyler et al., 2010b), performance on the task was most strongly related to responsivity of the domain-general MDN. Indeed, MDN responsivity, but not that of the other networks, also correlated with a measure of fluid intelligence performed outside the scanner ( $r=$ $0.26, p<0.01$, controlling for age; see Materials and Methods), further suggesting that the MDN plays a role in flexible adaptation to experimental demands across a wide range of tasks (Duncan and Owen, 2000). Nevertheless, in a moderation analysis, MDN responsivity did not interact with age to affect syntax performance $(t=1.26, p=0.21)$, suggesting that recruitment of this domain-general network aids performance at any age and is not simply a compensatory response among older adults.

\section{Within-network connectivity}

Connectivity during task and natural listening

The ICA identified a set of networks that relate to our conditions of interest, but how is the internal coherence of (or functional connectivity within) those networks affected by task manipulations, age, and gray matter decline? To address this question, we first quantified within-network connectivity as the average correlation between all pairs of voxels within the thresholded component maps (after detrending and regressing motion parameters from the raw fMRI time courses; see Materials and Methods). Mean connectivity within each network during task and natural listening is shown in Table 5. To determine whether task demands affect within-network connectivity, we submitted mean connectivity for each of our seven networks to a MANOVA with Task (task, natural listening) as a within-subjects factor. 
Table 5. Mean within-network connectivity during task and natural listening

\begin{tabular}{|c|c|c|c|c|c|}
\hline \multirow[b]{2}{*}{ Component } & \multirow[b]{2}{*}{ Task } & \multirow[b]{2}{*}{ Natural listening } & \multicolumn{3}{|l|}{ Task vs natural listening } \\
\hline & & & $M_{\text {diff }}(95 \%$ Cl $)$ & $t(110)$ & $p$ \\
\hline Frontotemporal & $0.43(0.08)$ & $0.43(0.07)$ & $0.007(-0.005,0.02)$ & 1.19 & 0.24 \\
\hline Auditory & $0.48(0.09)$ & $0.49(0.08)$ & $-0.006(-0.02,0.01)$ & -0.97 & 0.34 \\
\hline Multiple demand & $0.52(0.09)$ & $0.50(0.08)$ & $0.02(0.01,0.03)$ & 3.38 & $<0.01$ \\
\hline Opercular & $0.46(0.09)$ & $0.46(0.08)$ & $-0.001(-0.01,0.01)$ & -0.17 & 0.87 \\
\hline Basal ganglia & $0.49(0.08)$ & $0.48(0.08)$ & $0.004(-0.01,0.01)$ & 0.67 & 0.50 \\
\hline Motor & $0.57(0.08)$ & $0.55(0.08)$ & $0.02(0.004,0.03)$ & 2.61 & $<0.05$ \\
\hline Default mode & $0.54(0.09)$ & $0.54(0.08)$ & $0.002(-0.01,0.01)$ & 0.34 & 0.73 \\
\hline
\end{tabular}

Values in the two left columns reflect mean within-network connectivity (WNC) across participants during Task and Natural Listening (SD in parentheses). Right columns show results from follow-up paired samples $t$ test testing the difference in WNC between Task and Natural Listening.

Reporting the results of the omnibus multivariate test first, overall there was a main effect of Task: $T=0.39, F_{(7,104)}=5.80, p<$ $0.001, \eta_{p}^{2}=0.28$. Follow-up pairwise comparisons show that connectivity increased slightly from natural listening to task in the MDN: $t_{(110)}=3.38, M_{\text {diff }}=0.02, p<0.01,95 \%$ CI $(0.01$, $0.03), d=0.32$, and MOT network, $t_{(110)}=2.61, M_{\text {diff }}=0.02$, $p<0.05,95 \%$ CI $(0.004,0.03), d=0.25$, with no other networks differing between the two states (Table 5). Thus, connectivity within most of these networks remains remarkably stable across different experimental states, despite the increase in loading values (or relationship to task conditions) of many of these networks during the task. This is in line with previous work showing that the brain's functional architecture during active task performance is primarily determined by an intrinsic network structure that is also apparent at rest and across different task states, and to a lesser extent by domain-specific changes linked to a particular task (Cole et al., 2014; Krienen et al., 2014).

\section{Relationship to age and gray matter}

During both natural listening and the task, connectivity within the FTN did not differ with age. In fact, only the BG network showed a significant age-related decline (Table 3 ). We also examined the effect of mean GMC within each network on that network's within-network connectivity strength. Gray matter did not significantly relate to within-network connectivity during natural listening (Table 4), but it did relate to connectivity within some of the networks during the task (Table 4), with the MDN, OPRC, and BG surviving correction. Entering each of these networks into a regression predicting connectivity from age and GMC, as a means to determine the unique contribution of each factor, we see that connectivity within the MDN is predicted by $\operatorname{GMC}[\beta=0.34, t=2.92, p<0.01,95 \% \mathrm{CI}(0.11,0.58)]$, not age $\left[\beta=0.01, t=0.11, p=0.92,95 \% \mathrm{CI}(-0.23,0.26) ; \operatorname{model} R^{2}=\right.$ $\left.0.11, F_{(2,108)}=6.82, p<0.01\right]$; OPRC by GMC $[\beta=0.27, t=$ $2.30, p<0.05,95 \% \mathrm{CI}(0.04,0.49)]$, not age $[\beta=-0.07, t=0.64$, $p=0.53,95 \%$ CI $(-0.32,0.16)$; model $R^{2}=0.10, F_{(2,108)}=5.94$, $p<0.01]$; and BG by age $[\beta=-0.42, t=4.10, p<0.001,95 \% \mathrm{CI}$ $(-0.66,-0.23)]$, not GMC $[\beta=0.04, t=0.39, p=0.70,95 \% \mathrm{CI}$ $(-0.17,0.25)$; model $\left.R^{2}=0.20, F_{(2,108)}=13.47, p<0.001\right]$. Thus, connectivity within the MDN and OPRC networks related to GMC within these networks, regardless of age, whereas connectivity within the BG network showed a steep age-related decline which does not appear to be due to age-related declines in gray matter within that network.

\section{Relationship to performance}

Within-network connectivity was not significantly related to task performance for any of the individual networks $\left(r_{110}=0.11,0.21\right.$, $-0.00,0.08,0.09,0.05,0.01$, for the FTN, AUD, MDN, OPRC,
BG, MOT, and DMN, respectively; smallest $p=0.03$ for the AUD, which does not survive correction).

\section{Between-network connectivity}

\section{Connectivity during task and natural listening}

We have shown that relative to natural listening, task-based language comprehension recruits several networks in addition to the critical frontotemporal syntax system, but do these networks interact with the FTN to affect performance? To address this question, we calculated between-network connectivity as the correlation between each pair of network time courses during the task and natural listening separately (see Materials and Methods; Allen et al., 2011). As shown in Figure $3 a$, most networks were strongly connected to each other during the task, but less so during natural listening (Fig. $3 b$ ). Figure $3 c$ shows the difference in connectivity between the two experimental states $(p<0.05$, Bonferroni corrected). Between-network connectivity was stronger during the task than natural listening in most cases with the notable exception of FTN-AUD connectivity, which was stronger during natural listening. This finding fits well with the observation that only the FTN and AUD networks are active during natural listening, whereas a host of other networks come online during active task performance. Moreover, these domain-general networks show significantly greater connectivity to the critical frontotemporal syntax system during the task; this pattern suggests that this integration between networks has implications for task performance (see below).

\section{Relationship to within-network connectivity}

Is stronger between-network connectivity related to weaker within-network connectivity (as suggested by findings of decreased network segregation with age at rest; Chan et al., 2014; Geerligs et al., 2014)? To address this question, for each pair of networks (separately for task and natural listening), we calculated the correlation between within-network connectivity for each network in the pair and the connectivity between the two networks. As shown in Figure $3 d$, in general, stronger within network connectivity during the task related to stronger between network connectivity (and this relationship was not moderated by age, $t$ values $<2, p$ values $>0.10$, except for the age $\times$ MOTwithin interaction predicting MOT-DMN, $t=2.13, p=0.04$, and the age $\times$ DMN-within interaction predicting DMN-BG, $t=$ $2.24, p=0.03$, both of which do not survive correction). Natural listening shows a similar pattern to the task, in that stronger within relates to stronger between, but with fewer significant correlations (Fig. 3e), likely due to weaker connectivity between networks during natural listening (Fig. $3 c$ ). Focusing on the FTN during the task, we see that stronger connectivity within this network relates to stronger connections to other, domain-general 
A

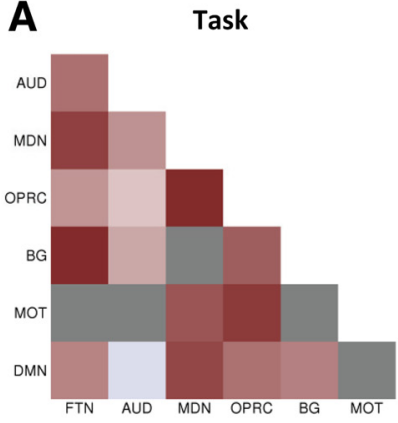

D

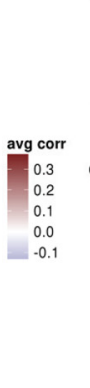

B

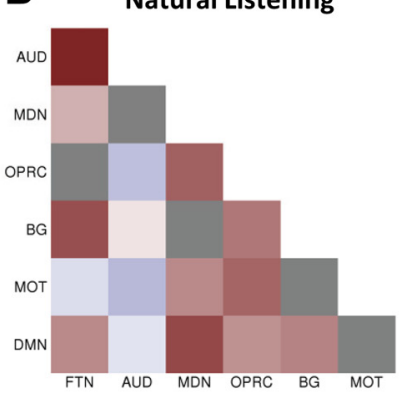

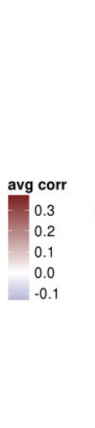

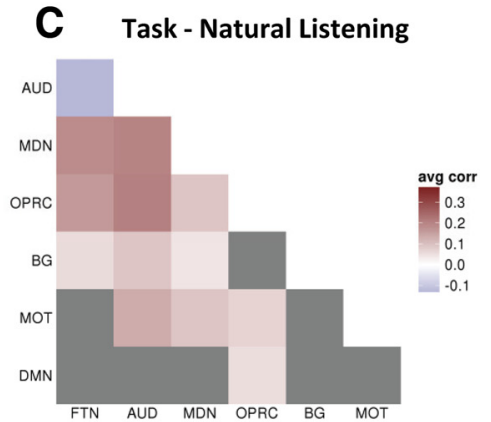

Corr between WNC and BNC during Task

E corr between WNC and BNC during Nat Listening
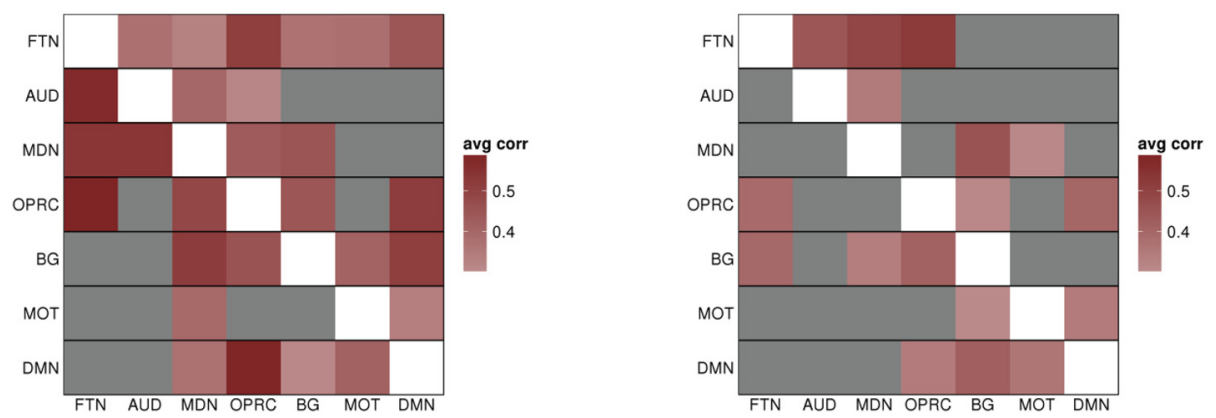

Figure 3. Effects of task and within-network connectivity (WNC) on between-network connectivity (BNC). BNC matrices for ( $\boldsymbol{A}$ ) Task and (B) Natural Listening. Pairwise correlations were computed between-subject-specific time courses for each of the seven networks and then averaged across participants. Color bar indicates the strength of the average correlation (avg corr), with gray squares indicating nonsignificant correlations ( $p>0.05$, Bonferroni corrected). C, Difference in BNC between task and natural listening. D, E, Asymmetrical matrices showing the correlation between WNC in each network and BNC during Task and Natural Listening, respectively. Network labels listed down the left-hand side signify both the WNC value being correlated, as well as one of the networks in each BNC pair (the other is listed along the bottom).

networks (and as mentioned above, this does not differ with age), further reiterating the fact that these between-network connections are likely not compensatory (i.e., in response to decreased within-network connectivity; cf. Meunier et al., 2014) but reflect normal systems-level interactions in the service of task goals.

\section{Relationship to age and gray matter}

We were primarily interested in the effect of age and GMC on between-network connectivity during the task, when all seven networks were most strongly activated (however, for the sake of completeness, the same analyses are shown for the Natural Listening condition in Fig. $4 c, d$ ). Figure $4 a$ shows the relationship between age and between-network connectivity during the task $(p<0.05$, Bonferroni corrected). Age was associated with decreased connectivity during the task between the following network pairs: FTN-AUD, FTN-MDN, AUD-MDN, AUD-DMN, BG-OPRC, BG-DMN, and MOT-OPRC. In contrast, connectivity increased with increasing age between the AUD-BG networks, and between the MDN-DMN systems. A similar, but less robust, pattern of results is seen for GMC (averaged across both networks in the pair; Fig. 4b). More gray matter was associated with stronger connectivity between the FTN-MDN, AUD-MDN, and BGOPRC networks, whereas less gray matter was associated with stronger connectivity between the MDN-DMN networks.

To determine whether age and gray matter make independent contributions to functional connectivity between the FTNMDN, AUD-MDN, MDN-DMN, and OPRC-BG, we entered each network pair into a regression predicting between-network connectivity from age and mean GMC. We found that connectivity between the FTN-MDN is predicted by age $[\beta=-0.37, t=$ $3.50, p<0.001,95 \% \mathrm{CI}(-0.61,-0.17)]$, with a trend for GMC $\left(\beta=0.18, t=1.72, p=0.088,95 \% \mathrm{CI}(-0.03,0.40) ; \operatorname{model} R^{2}=\right.$ $\left.0.26, F_{(2,108)}=18.98, p<0.001\right]$; AUD-MDN connectivity is predicted by age $[\beta=-0.50, t=5.07, p<0.001,95 \% \mathrm{CI}(-0.73$, $-0.32)]$, not GMC $\left(p=0.32\right.$; model $R^{2}=0.32, F_{(2,108)}=25.57$, $p<0.001)$; MDN-DMN connectivity is predicted by age $[\beta=$ $0.36, t=3.30, p<0.01,95 \% \mathrm{CI}(0.15,0.60)$, not GMC ( $p=0.24$; model $\left.R^{2}=0.21, F_{(2,108)}=13.88, p<0.001\right)$; and OPRC-BG connectivity is predicted by both age $[\beta=-0.40, t=4.11, p<$ $0.001,95 \% \mathrm{CI}(-0.62,-0.22)]$ and $\mathrm{GMC}[\beta=0.26, t=2.68, p<$ $0.01,95 \%$ CI $(0.07,0.45)$; model $R^{2}=0.36, F_{(2,108)}=29.91$, $p<0.001]$. Thus, between-network connectivity was most strongly related to age, with GMC only making an independent contribution to some of the network pairs.

\section{Relationship to task performance}

In line with the critical role of the frontotemporal network in syntactic processing, performance on the task only related to functional connectivity between the FTN and other networks (Fig. 5a). Specifically, better performance related to stronger connectivity between the FTN-MDN $[r=0.24, p=0.01,95 \% \mathrm{CI}$ $(0.05,0.40)]$ and FTN-OPRC $[r=0.25, p=0.008,95 \%$ CI $(0.09$, $0.41)]$. Further, between-network connectivity did not interact with age to predict performance $(t=1.46, p=0.15$, and $t=0.24$, $p=0.81$, for the interaction between age and the FTN-MDN and FTN-OPRC, respectively), suggesting that connectivity between the FTN and these domain-general networks is not a compensatory response, but rather contributes to successful performance across the lifespan. Moreover, if we enter average connectivity between these networks (FTN-MDN and FTN-OPRC) into a regression model with FTN responsivity to predict performance, the overall model is significant: $R^{2}=0.10, F_{(2,107)}=6.06, p<$ 0.01 , and we see that between-network connectivity is a significant predictor $[\beta=0.26, t=2.76, p<0.01,95 \% \mathrm{CI}(0.07,0.43)]$, 
A

\section{Corr between Age and BNC during Task}

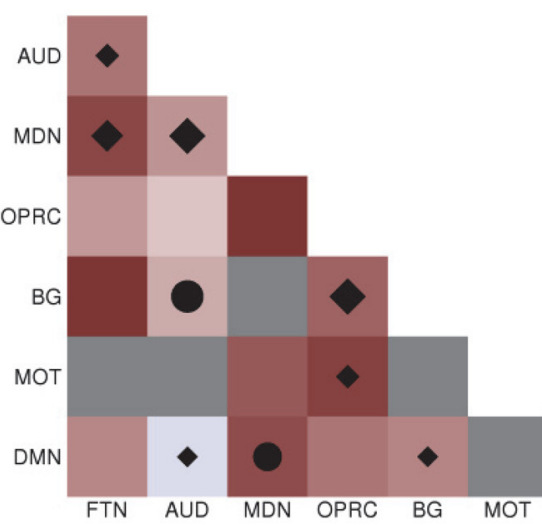

C

\section{Corr between Age and BNC during Natural Listening}
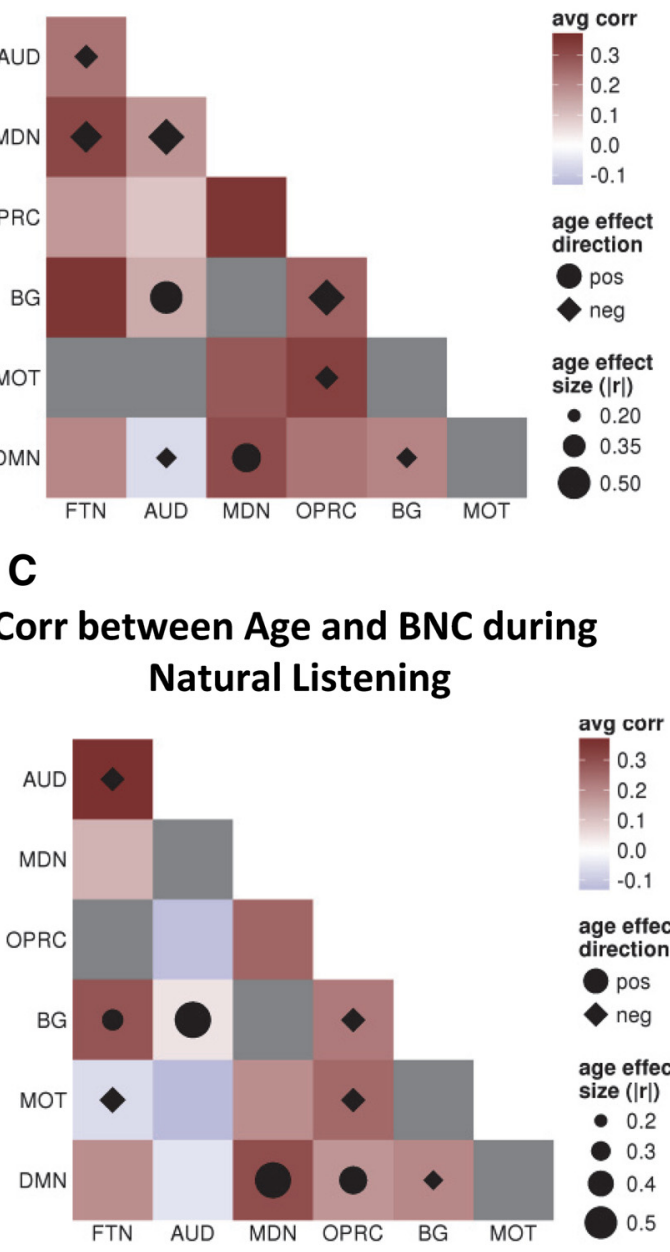

B

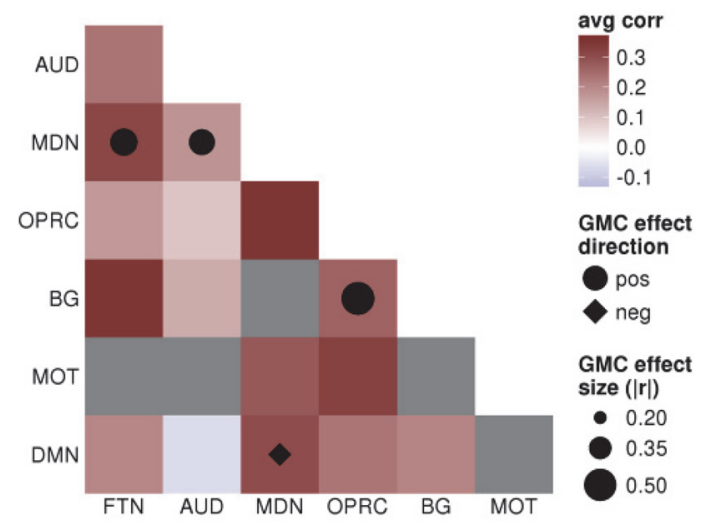

D

\section{Corr between GMC and BNC during Natural Listening}

Figure 4. Relationship of between-network connectivity (BNC) to age and gray matter during the task $(\boldsymbol{A}, \boldsymbol{B})$ and natural listening $(\boldsymbol{C}, \boldsymbol{D})$. Background color indicates average BNC strength. Black dots indicate the correlation between BNC and age or GMC, with diamonds indicating a negative relationship and circles indicating a positive relationship. The size of the dot indicates the strength of the correlation. Some of the effects seen during the task are also replicated during Natural Listening (e.g., age to AUD-FTN, MDN-DMN, and GMC to MDN-DMN), whereas other effects are novel.

whereas the FTN alone is not $[\beta=0.15, t=1.55, p=0.13,95 \%$ CI $(-0.04,0.32)]$. Together, these findings suggest that explicit task performance is not a straightforward reflection of FTN responsivity, but a mixture of the FTN (doing syntactic computations), and other, more domain-general networks contributing task-related processing.

\section{Effect of crystallized knowledge on performance}

If functional connectivity between the FTN and MDN is positively related to performance on the task, but negatively affected by age and decreasing gray matter, how is it that performance remains stable across the lifespan? Some work suggests that age differences on tasks which place heavy demands on domaingeneral processes (and typically decline with age) are sometimes minimized when older adults can make use of existing knowledge (Charness, 1981; Castel, 2005; Soederberg Miller, 2009). Indeed, this may be the case during normal language comprehension, which depends on well practiced, largely automatized processes and highly familiar language inputs (Marslen-Wilson and Tyler, 1975; Zhuang et al., 2014). Thus, we might expect that preserved performance on this task may become increasingly dependent on crystallized knowledge with age, potentially compensating for decreased domain-general control. To test this, we entered age, crystallized knowledge, and the age $\times$ crystallized knowledge interaction into a regression model predicting task performance, controlling for fluid intelligence (which is known to correlate with crystallized intelligence; Cattell, 1963). The model was significant: $R^{2}=0.18, F_{(4,105)}=7.53, p<0.001$, and while the main effect of age was not significant $[\beta=0.16, t=1.60, p=0.11,95 \%$ CI $(-0.04,0.37)]$, there were main effects of fluid intelligence $[\beta=0.29, t=2.38, p<0.05,95 \% \mathrm{CI}(0.05,0.52])$ and knowledge $[\beta=0.22, t=2.24, p<0.05,95 \% \mathrm{CI}(0.03,0.42)])$, and importantly, an age $\times$ knowledge interaction $[\beta=0.26, t=2.05, p<$ $0.05,95 \%$ CI $(0.01,0.50)]$. This interaction appears to be due to crystallized knowledge becoming increasingly related to task performance with age (Fig. 5b). Separate regression analyses performed in each age group (group N's provided in Table 1) confirms this, with crystallized intelligence becoming a significant predictor of task performance in the oldest group [young: model $F<1, \beta_{\text {crystallized }}=0.09, t=0.73, p=0.47$; middle-aged: model $F<1, \beta_{\text {crystallized }}=0.11, t=0.66, p=0.51$; older: overall model $R^{2}=0.32, F_{(2,36)}=8.60, p<0.001, \beta_{\text {crystallized }}=0.46, t=$ $3.30, p<0.01,95 \%$ CI $(0.20,0.83), \beta_{\text {fluid }}=0.26, t=1.85, p=$ $0.07,95 \%$ CI $(-0.04,0.80)]$. Thus, older adults may be able to 
compensate for age-related declines in domain-general abilities by relying more heavily on an ever-growing body of crystallized knowledge.

\section{Discussion}

We used a systems-level approach to separate processes specific to language comprehension from those related to general task demands and to interrogate age differences in functional connectivity both within and between those systems in the service of syntactic processing. We show that task-free language comprehension solely recruits the auditory and frontotemporal syntax networks, whereas active task performance calls upon several additional networks, which interact with the critical FTN to predict overt task performance. Despite age-related declines in FTN gray matter, functionality of this network remains remarkably intact with age, showing no age-related difference in within-network connectivity or responsivity to syntactic processing demands. However, in the context of a task, although aging did not affect the expression of individual networks, connectivity between the FTN and MDN decreased with age, suggesting that even if a network remains functionally intact with age, its ability to flexibly interact with other networks in the service of task goals may be affected. However, despite the decline in FTN-MDN connectivity with age, we found that overt task performance was maintained across the lifespan, possibly due to older adults' richer reserve of verbal knowledge, which helps to offset fluid declines.

The BOLD activity measured with fMRI represents a mix of signals from different sources within the brain. ICA allows for the separation of those signals (Calhoun et al., 2009; Beckmann, 2012) and in this case, enabled us to tease apart those networks which are required for syntactic processing from those required for general task demands. This method, combined with our use of two versions of the same syntactic processing experiment (one which isolated our cognitive process of interest, and another which introduced simple task demands common to many cognitive experiments), allowed us to more accurately characterize the nature of age-related functional differences. Contrary to previous reports of an agerelated increase in right-frontal activation during language comprehension (Peelle et al., 2010; Tyler et al., 2010a), we did not find evidence for this "compensatory" response, either during task-free language comprehension or during the active task version. We have argued previously that the topography of the core frontotemporal syntax network changes little with age (Davis et al., 2014; Shafto and Tyler, 2014), and that increased right-frontal activation commonly identified using standard univariate analysis methods may actually be attrib- utable to task-related processes; processes that would fall under the purview of domain-general networks if the covariance between regions was taken into account.

In this case, we did not observe an age-related increase in the activation of frontal control networks. Furthermore, increased reactivity of the MDN, as well as greater FTN-MDN connectivity, related to better task performance across the lifespan (i.e., was not moderated by age), suggesting that this was not a compensatory response in older adults, but related to better performance in all participants. These divergent findings may be due to the population-representativeness of our sample. Our recruitment process excluded term-time students (Shafto et al., 2014), and thus, our sample of younger adults was more diverse than those typically used in psychological experiments, which primarily consist of students from (often top-tier) universities. Thus, the task may have been similarly demanding to all of our participants and as a result, we did not observe an age-related increase in frontal control regions that older adults 
typically show at lower levels of demand (Reuter-Lorenz and Cappell, 2008).

Another aim of the study was to examine the effect of age and experimental task demands on functional connectivity both within and between ICA-identified networks. Previous work examining the effect of age on large-scale network organization has primarily focused on the resting state (Ferreira and Busatto, 2013) or age differences in large-scale systems (such as the DMN and FPN, the precise functions of which remain unclear) during attentionally demanding tasks (Madden et al., 2010; Clapp et al., 2011; Spreng and Schacter, 2012; Geerligs et al., 2015a), but no study to date has isolated a higher-order network with as clearly defined a function as the FTN (Tyler et al., 2011) and examined how age and task demands affect both its internal functioning and interactivity with other networks. We found that connectivity within this network, as well as other domain-general networks, changed very little moving from natural listening to task (although the MDN and MOT did show a modest increase), suggesting that network architecture remains remarkably stable across varying task states (Cole et al., 2014; Krienen et al., 2014; Geerligs et al., 2015b). Functional connectivity between networks, on the other hand, increased during active task performance, particularly between networks generally thought to be responsible for attentional control (MDN, OPRC; Dosenbach et al., 2008; Duncan, 2010) and those responsible for sound/language processing (AUD, FTN), likely reflecting the reliance of task-based decisions on auditory and linguistic processing output. Although only the BG showed a significant decline in withinnetwork connectivity with age, between-network connectivity decreased with age during the task for several network pairs (although MDN-DMN and AUD-BG connectivity increased). Although some work has shown an age-related decline in network segregation during rest (i.e., decreased within-network connectivity coupled with increased between; Chan et al., 2014; Geerligs et al., 2014), we see little evidence of this during an active language comprehension task. Thus, age differences in functional connectivity observed at rest may not extrapolate to cognitive tasks.

One of the most remarkable findings of this study is the maintained functionality of the frontotemporal syntax system, despite age-related declines in gray matter integrity and disrupted connectivity to task-related networks. Unlike the reduced function seen after focal damage to the FTN (Tyler et al., 2010b, 2011), which itself tends to track with the extent of the damage (Wright et al., 2012), the relatively diffuse and gradual reduction in structural integrity associated with normal aging seems to have little effect on FTN function. This may be because syntactic processing is a relatively automatic process (Marslen-Wilson and Tyler, 1975), involving a set of obligatory computations and relying on a separate pool of "resources" from conscious, control processes (Waters and Caplan, 1996). Compared with effortful control, automatic processes are thought to be relatively preserved with age (Hasher and Zacks, 1979). As long as the input is audible (Gordon-Salant and Fitzgibbons, 1997; Pichora-Fuller, 2003) and not presented too quickly (Wingfield et al., 1999, 2003), both older and younger adults alike obligatorily (and rapidly) integrate the syntactic and semantic properties of each word into an online sentential representation. However, it remains unclear, from a neural perspective, why automatic processes are preserved while controlled processes decline. Both cross-sectional and longitudinal work suggests that frontal control regions tend to be more affected by age than more posterior regions (Raz et al., 2005, 2010; Peelle et al., 2012), with the latter more closely tied to obligatory functions [e.g., object recognition (Clarke and Tyler, 2015); reading (Gold et al., 2009); memory binding (Moscovitch, 1992)]. Indeed, in our sample, gray matter within the left inferior frontal cortex (BA44, 45, and 47) declined more with age $\left[r_{111}=\right.$ $-0.68, p<0.001,95 \%$ CI $(-0.77,-0.56)]$ than that within the MTG [BA 21 and 22; $r_{111}=-0.51, p<0.001,95 \%$ CI $(-0.63$, -0.36 ); Meng's $Z$ test for dependent correlations sharing a variable: $Z=3.25, p=0.001$ ], albeit decline within the MTG was clearly substantial. It may be that this relative preservation of structure in the MTG is sufficient to sustain connectivity with the left inferior frontal cortex and maintain functionality. A critical question for future research is how much is enough? That is, at what point do structural declines become so great that automatic processes, such as syntax, start to break down?

Finally, we show that when language comprehension occurs within the context of a task, even a simple task conducted online, successful performance relates most strongly to the MDN, a network previously shown to be under-recruited by older adults as attentional demands increase (Cappell et al., 2010; Nagel et al., 2011; Campbell et al., 2012). Despite the observed age-related decline in FTN-MDN connectivity during the task, overt performance on the task did not differ. Older, but not younger, adults with higher crystallized intelligence performed better on the syntax task, in line with previous work showing that older adults can make up for generalized declines with increased domain-specific knowledge (Charness, 1981; Salthouse, 1984; Soederberg Miller, 2009). Future work, with better temporal resolution (Tyler et al., 2013), is required to determine whether this benefit of verbal knowledge to performance arises from better prediction of upcoming words, faster revision of misinterpreted ambiguities, or postsyntactic decision processes.

Our aim was to gain a more accurate picture of neurocognitive aging by separating natural language comprehension from taskbased processes which are far from natural. In our view, this separation of domain-specific from domain-general processes is a necessary step to move beyond ill-defined terms, such as "dedifferentiation" and "compensation," to more detailed models of how age affects the instantiation of specific cognitive processes in the brain. A challenge going forward will be to find ways to test other cognitive functions (e.g., memory encoding and retrieval, verbal production) in more naturalistic ways (Stephens et al., 2010; Hall et al., 2014; Campbell et al., 2015), minimizing task demands. We are ultimately interested in how age affects the brain and cognition, not the task itself.

\section{References}

Allen EA, Erhardt EB, Damaraju E, Gruner W, Segall JM, Silva RF, Havlicek M, Rachakonda S, Fries J, Kalyanam R, Michael AM, Caprihan A, Turner JA, Eichele T, Adelsheim S, Bryan AD, Bustillo J, Clark VP, Feldstein Ewing SW, Filbey F, et al. (2011) A baseline for the multivariate comparison of resting-state networks. Front Syst Neurosci 5:2. Medline

Arbabshirani MR, Havlicek M, Kiehl KA, Pearlson GD, Calhoun VD (2013) Functional network connectivity during rest and task conditions: a comparative study. Hum Brain Mapp 34:2959-2971. CrossRef Medline

Ashburner J (2007) A fast diffeomorphic image registration algorithm. Neuroimage 38:95-113. CrossRef Medline

Ashburner J, Friston KJ (2005) Unified segmentation. Neuroimage 26:839851. CrossRef Medline

Baddeley A, Emslie H, Nimmo-Smith I (1993) The spot-the-word test: a robust estimate of verbal intelligence based on lexical decision. Br J Clin Psychol 32:55-65. CrossRef Medline

Beckmann CF (2012) Modelling with independent components. Neuroimage 62:891-901. CrossRef Medline

Buckner RL, Kelley WM, Petersen SE (1999) Frontal cortex contributes to human memory formation. Nat Neurosci 2:311-314. CrossRef Medline Calhoun VD, Adali T, Pearlson GD, Pekar JJ (2001) A method for making 
group inferences from functional MRI data using independent component analysis. Hum Brain Mapp 14:140-151. CrossRef Medline

Calhoun VD, Kiehl KA, Pearlson GD (2008) Modulation of temporally coherent brain networks estimated using ICA at rest and during cognitive tasks. Hum Brain Mapp 29:828-838. CrossRef Medline

Calhoun VD, Liu J, Adali T (2009) A review of group ICA for fMRI data and ICA for joint inference of imaging, genetic, and ERP data. Neuroimage 45:S163-S172. CrossRef Medline

Campbell KL, Grady CL, Ng C, Hasher L (2012) Age differences in the frontoparietal cognitive control network: implications for distractibility. Neuropsychologia 50:2212-2223. CrossRef Medline

Campbell KL, Shafto MA, Wright P, Tsvetanov KA, Geerligs L, Cusack R, Cam-CAN, Tyler LK (2015) Idiosyncratic responding during moviewatching predicted by age differences in attentional control. Neurobiol Aging 36:3045-3055. CrossRef Medline

Caplan D, Hildebrandt N, Makris N (1996) Location of lesions in stroke patients with deficits in syntactic processing in sentence comprehension. Brain 119:933-949. CrossRef Medline

Cappell KA, Gmeindl L, Reuter-Lorenz PA (2010) Age differences in prefontal recruitment during verbal working memory maintenance depend on memory load. Cortex 46:462-473. CrossRef Medline

Castel AD (2005) Memory for grocery prices in younger and older adults: the role of schematic support. Psychol Aging 20:718-721. CrossRef Medline

Cattell RB (1963) Theory of fluid and crystallized intelligence: a critical experiment. J Educ Psychol 54:1-22. CrossRef

Cattell RB, Cattell AKS (1960) Handbook for the individual or group culture fair intelligence test. Savoy, IL: Institute for Personality and Ability Testing.

Chan MY, Park DC, Savalia NK, Petersen SE, Wig GS (2014) Decreased segregation of brain systems across the healthy adult lifespan. Proc Natl Acad Sci U S A 111:E4997-E5006. CrossRef Medline

Charness N (1981) Search in chess: age and skill differences. J Exp Psychol Hum Percept Perform 7:467-476. CrossRef

Clapp WC, Rubens MT, Sabharwal J, Gazzaley A (2011) Deficit in switching between functional brain networks underlies the impact of multitasking on working memory in older adults. Proc Natl Acad Sci U S A 108:72127217. CrossRef Medline

Clarke A, Tyler LK (2015) Understanding what we see: how we derive meaning from vision. Trends Cogn Sci 19:677-687. CrossRef Medline

Cole MW, Bassett DS, Power JD, Braver TS, Petersen SE (2014) Intrinsic and task-evoked network architectures of the human brain. Neuron 83: 238-251. CrossRef Medline

Cusack R, Vicente-Grabovetsky A, Mitchell DJ, Wild CJ, Auer T, Linke AC, Peelle JE, Gardner D, Cornell W, Irimia A (2015) Automatic analysis (aa): efficient neuroimaging workflows and parallel processing using Matlab and XML. Front Neuroinform 8:1-13. CrossRef

Davis SW, Zhuang J, Wright P, Tyler LK (2014) Age-related sensitivity to task-related modulation of language-processing networks. Neuropsychologia 63:107-115. CrossRef Medline

Dosenbach NU, Visscher KM, Palmer ED, Miezin FM, Wenger KK, Kang HC, Burgund ED, Grimes AL, Schlaggar BL, Petersen SE (2006) A core system for the implementation of task sets. Neuron 50:799-812. CrossRef Medline

Dosenbach NU, Fair DA, Cohen AL, Schlaggar BL, Petersen SE (2008) A dual-networks architecture of top-down control. Trends Cogn Sci 12: 99-105. CrossRef Medline

Duncan J (2010) The multiple-demand (MD) system of the primate brain: mental programs for intelligent behaviour. Trends Cogn Sci 14:172-179. CrossRef Medline

Duncan J, Owen AM (2000) Common regions of the human frontal lobe recruited by diverse cognitive demands. Trends Neurosci 23:475-483. CrossRef Medline

Ferreira LK, Busatto GF (2013) Resting-state functional connectivity in normal brain aging. Neurosci Biobehav Rev 37:384-400. CrossRef Medline

Folstein MF, Folstein SE, McHugh PR (1975) "Mini mental state": a practical method for grading the cognitive state of patients for the clinician. J Psychiatr Res 12:189-198. CrossRef Medline

Geerligs L, Maurits NM, Renken RJ, Lorist MM (2014) Reduced specificity of functional connectivity in the aging brain during task performance. Hum Brain Mapp 35:319-330. CrossRef Medline

Geerligs L, Renken RJ, Saliasi E, Maurits NM, Lorist MM (2015a) A brain- wide study of age-related changes in functional connectivity. Cereb Cortex 25:1987-1999. CrossRef Medline

Geerligs L, Rubinov M, Cam-CAN, Henson RN (2015b) State and trait components of functional connectivity: individual differences vary with mental state. J Neurosci 35:13949-13961. CrossRef Medline

Gold BT, Andersen AH, Jicha GA, Smith CD (2009) Aging influences the neural correlates of lexical decision but not automatic semantic priming. Cereb Cortex 19:2671-2679. CrossRef Medline

Gordon-Salant S, Fitzgibbons PJ (1997) Selected cognitive factors and speech recognition performance among young and elderly listeners. J Speech Lang Hear Res 40:423-431. CrossRef Medline

Grady C (2012) The cognitive neuroscience of ageing. Nat Rev Neurosci 13:491-505. CrossRef Medline

Hagoort P, Wassenaar M, Brown C (2003) Real-time semantic compensation in patients with agrammatic comprehension: electrophysiological evidence for multiple-route plasticity. Proc Natl Acad Sci U S A 100: 4340-4345. CrossRef Medline

Hall SA, Rubin DC, Miles A, Davis SW, Wing EA, Cabeza R, Berntsen D (2014) The neural basis of involuntary episodic memories. J Cogn Neurosci 26:2385-2399. CrossRef Medline

Hasher L, Zacks RT (1979) Automatic and effortful processes in memory. J Exp Psychol Gen 108:356-388.

Krienen FM, Yeo BT, Buckner RL (2014) Reconfigurable task-dependent functional coupling modes cluster around a core functional architecture. Philos Trans R Soc Lond B Biol Sci 369:20130526. CrossRef Medline

Laird AR, Fox PM, Eickhoff SB, Turner JA, Ray KL, McKay DR, Glahn DC, Beckmann CF, Smith SM, Fox PT (2011) Behavioral interpretations of intrinsic connectivity networks. J Cogn Neurosci 23:4022-4037. CrossRef Medline

Madden DJ, Costello MC, Dennis NA, Davis SW, Shepler AM, Spaniol J, Bucur B, Cabeza R (2010) Adult age differences in functional connectivity during executive control. Neuroimage 52:643-657. CrossRef Medline

Marslen-Wilson W, Tyler LK (1975) Processing structure of sentence perception. Nature 257:784-786. CrossRef Medline

Meunier D, Stamatakis EA, Tyler LK (2014) Age-related functional reorganization, structural changes, and preserved cognition. Neurobiol Aging 35:42-54. CrossRef Medline

Morcom AM, Johnson W (2015) Neural reorganization and compensation in aging. J Cogn Neurosci 27:1275-1285. CrossRef Medline

Moscovitch M (1992) Memory and working-with-memory: a component process model based on modules and central systems. J Cogn Neurosci 4:257-267. CrossRef Medline

Nagel IE, Preuschhof C, Li SC, Nyberg L, Bäckman L, Lindenberger U, Heekeren HR (2011) Load modulation of BOLD response and connectivity predicts working memory performance in younger and older adults. J Cogn Neurosci 23:2030-2045. CrossRef Medline

Peelle JE, Troiani V, Wingfield A, Grossman M (2010) Neural processing during older adults' comprehension of spoken sentences: age differences in resource allocation and connectivity. Cereb Cortex 20:773-782. CrossRef Medline

Peelle JE, Cusack R, Henson RN (2012) Adjusting for global effects in voxelbased morphometry: gray matter decline in normal aging. Neuroimage 60:1503-1516. CrossRef Medline

Pichora-Fuller MK (2003) Cognitive aging and auditory information processing. Int J Audiol 42:2S26-2S32. Medline

Ratcliff R (1993) Methods for dealing with RT outliers. Psychol Bull 114: 510-532. CrossRef Medline

Ray KL, McKay DR, Fox PM, Riedel MC, Uecker AM, Beckmann CF, Smith SM, Fox PT, Laird AR (2013) ICA model order selection of task coactivation networks. Front Neurosci 7:237. CrossRef Medline

Raz N, Lindenberger U, Rodrigue KM, Kennedy KM, Head D, Williamson A, Dahle C, Gerstorf D, Acker JD (2005) Regional brain changes in aging healthy adults: general trends, individual differences and modifiers. Cereb Cortex 15:1676-1689. CrossRef Medline

Raz N, Ghisletta P, Rodrigue KM, Kennedy KM, Lindenberger U (2010) Trajectories of brain aging in middle-aged and older adults: regional and individual differences. Neuroimage 51:501-511. CrossRef Medline

Reuter-Lorenz PA, Cappell KA (2008) Neurocognitive aging and the compensation hypothesis. Curr Dir Psychol Sci 17:177-182. CrossRef

Salthouse TA (1984) Effects of age and skill in typing. J Exp Psychol Gen 113:345-371. CrossRef Medline

Sambataro F, Murty VP, Callicott JH, Tan HY, Das S, Weinberger DR, Mattay 
VS (2010) Age-related alterations in default mode network: impact on working memory performance. Neurobiol Aging 31:839-852. CrossRef Medline

Satterthwaite TD, Elliott MA, Gerraty RT, Ruparel K, Loughead J, Calkins ME, Eickhoff SB, Hakonarson H, Gur RC, Gur RE, Wolf DH (2013) An improved framework for confound regression and filtering for control of motion artifact in the preprocessing of resting-state functional connectivity data. Neuroimage 64:240-256. CrossRef Medline

Shafto MA, Tyler LK (2014) Language in the aging brain: the network dynamics of cognitive decline and preservation. Science 346:583-587. CrossRef Medline

Shafto MA, Tyler LK, Dixon M, Taylor JR, Rowe JB, Cusack R, Calder AJ, Marslen-Wilson WD, Duncan J, Dalgleish T, Henson RN, Brayne C, Matthews FE (2014) The Cambridge Centre for Ageing and Neuroscience (Cam-CAN) study protocol: a cross-sectional, lifespan, multidisciplinary examination of healthy cognitive ageing. BMC Neurol 14:204. CrossRef Medline

Smith SM, Fox PT, Miller KL, Glahn DC, Fox PM, Mackay CE, Filippini N, Watkins KE, Toro R, Laird AR, Beckmann CF (2009) Correspondence of the brain's functional architecture during activation and rest. Proc Natl Acad Sci U S A 106:13040-13045. CrossRef Medline

Snellen H (1862) Probebuchstaben zur bestimmung der sehscharfe (Van de Weijer, Utrecht).

Soederberg Miller LM (2009) Age differences in the effects of domain knowledge on reading efficiency. Psychol Aging 24:63-74. CrossRef Medline

Spreng RN, Schacter DL (2012) Default network modulation and largescale network interactivity in healthy young and old adults. Cereb Cortex 22:2610-2621. CrossRef Medline

Squire LR (1992) Memory and the hippocampus: a synthesis from findings with rats, monkeys, and humans. Psychol Rev 99:195-231. CrossRef Medline

Stephens GJ, Silbert LJ, Hasson U (2010) Speaker-listener neural coupling underlies successful communication. Proc Natl Acad Sci U S A 107: 14425-14430. CrossRef Medline

St Jacques PL, Kragel PA, Rubin DC (2011) Dynamic neural networks supporting memory retrieval. Neuroimage 57:608-616. CrossRef Medline

Tyler LK, Marslen-Wilson WD (1977) The on-line effects of semantic con- text on syntactic processing. J Verbal Learning Verbal Behav 16:683-692. CrossRef

Tyler LK, Shafto MA, Randall B, Wright P, Marslen-Wilson WD, Stamatakis EA (2010a) Preserving syntactic processing across the adult life span: the modulation of the frontotemporal language system in the context of agerelated atrophy. Cereb Cortex 20:352-364. CrossRef Medline

Tyler LK, Wright P, Randall B, Marslen-Wilson WD, Stamatakis EA (2010b) Reorganization of syntactic processing following left-hemisphere brain damage: does right-hemisphere activity preserve function? Brain 133: 3396-3408. CrossRef Medline

Tyler LK, Marslen-Wilson WD, Randall B, Wright P, Devereux BJ, Zhuang J, Papoutsi M, Stamatakis EA (2011) Left inferior frontal cortex and syntax: function, structure and behaviour in patients with left hemisphere damage. Brain 134:415-431. CrossRef Medline

Tyler LK, Cheung TP, Devereux BJ, Clarke A (2013) Syntactic computations in the language network: characterizing dynamic network properties using representational similarity analysis. Front Psychol 4:271. CrossRef Medline

Uppenkamp S, Johnsrude IS, Norris D, Marslen-Wilson W, Patterson RD (2006) Locating the initial stages of speech-sound processing in human temporal cortex. Neuroimage 31:1284-1296. CrossRef Medline

Waters GS, Caplan D (1996) The capacity theory of sentence comprehension: critique of just and carpenter (1992). Psychol Rev 103:761-772. CrossRef Medline

Wingfield A, Grossman M (2006) Language and the aging brain: patterns of neural compensation revealed by functional brain imaging. J Neurophysiol 96:2830-2839. CrossRef Medline

Wingfield A, Tun PA, Koh CK, Rosen MJ (1999) Regaining lost time: adult aging and the effect of time restoration on recall of time-compressed speech. Psychol Aging 14:380-389. CrossRef Medline

Wingfield A, Peelle JE, Grossman M (2003) Speech rate and syntactic complexity as multiplicative factors in speech comprehension by young and older adults. Aging Neuropsychol Cogn 10:310-322. CrossRef

Wright P, Stamatakis EA, Tyler LK (2012) Differentiating hemispheric contributions to syntax and semantics in patients with left-hemisphere lesions. J Neurosci 32:8149-8157. CrossRef Medline

Zhuang J, Tyler LK, Randall B, Stamatakis EA, Marslen-Wilson WD (2014) Optimally efficient neural systems for processing spoken language. Cereb Cortex 24:908-918. CrossRef Medline 